\title{
As pesquisas na Bahia sobre os afro-brasileiros
}

\author{
ENTREVISTA DE WALDIR FREITASOLIVEIRA
}

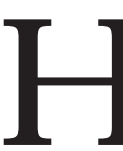

Á M AIS DE U M SÉCU Lo começaram na Bahia as pesquisas sobre os escravos trazidos da África nos navios negreiros. D esde N ina Rodrigues, inúmeros cientistas estudaram a evolução e a problemática dos negros, um tema fundamental, tendo em vista a presença majoritária dos afro-descendentes na cidade de Salvador.

E m razão disso, foi bastante significativa a contribuição de Arthur Ramos, É dison C arneiro, Pierre Verger, L uiz Viana Filho, além de outros pesquisadores, para esses estudos, bem como os trabalhos de pesquisa do Centro de Estudos Afro-O rientais (CEAO), uma instituição da U niversidade Federal da Bahia.

Para registrar essa trajetória, entrevistamos, no dia 9 de fevereiro, o professor Waldir Freitas O liveira que, durante onze anos, dirigiu o CEAO .

E STU D os A va N ÇA D os - C omo o sr. analisa o trabalho dos antropólogos, historiadores e cientistas sociais que pesquisaram, na Bahia, as comunidades afrobrasileiras e o preconceito racial?

Waldir Frei tasOlivei ra - Essas pesquisas foram iniciadas por $\mathrm{N}$ ina R odrigues, seguidas por Arthur Ramose, finalmente, naquela época, por É dison Carneiro. Este, com o apoio de Arthur Ramos e Áydano do Couto Ferraz e outros mais, organizaram, na Bahia, em 1937, o II Congresso Afro-Brasileiro. N aquela reunião pretenderam, de uma certa forma, mostrar aos pernambucanos que haviam realizado em Recife, em 1934, liderados por Gilberto Freyre, o I Congresso AfroB rasileiro. N ós, em Salvador, tínhamos idéias próprias sobre o problema do negro. I sso porque não concordávamos, integralmente, com a concepção de Gilberto Freyre sobre a formação social do Brasil e com a sua teoria sobre relações raciais.

$\mathrm{N}$ aquele encontro houve a tentativa da criação em Salvador de um núcleo de pesquisas dedicadas ao estudo da escravidão. M as esse objetivo não foi adiante porque, com a insurreição comunista de 1935, É dison Carneiro esteve ameaçado de ser preso. E também porque, logo em seguida, veio o Estado $\mathrm{N}$ ovo. D esse modo, aconteceu uma paral isação nessas atividades e ficamos, por algum tempo, sem estudos africanistas na Bahia. M esmo assim, em 1937, É dison Carneiro publicou seu livro de estréia $\mathrm{N}$ egros bantus, editado no Rio de J aneiro.

H ouve, então, um intervalo de alguns anos nessas pesquisas; mas, em 1946, foi lançado, também no Rio de Janeiro, um importante livro, escrito por Luís 
Viana Filho, chamado 0 negro na Bahia. Este livro não é só um trabalho de pesquisa, mas também um arquivo documental.

Em 1948 foi lançado, desta vez, na Bahia, o livro Candomblés da Bahia, de É dison Carneiro, que já havia, no entanto, a esse tempo, se transferido para o Rio de J aneiro. D epois, em 1957, houve uma contribuição muito boa para os estudos africanistas com a edição em D acar, no Senegal, do livro N otessur leculte desorisa et vodun à Bahia, la Bai edetouslesSaints, au Brésil et à l'ancienneC ôtedesesclaves em A frique, de autoria de Pierre Verger, editado pelo I nstitut Français d'Afrique N oire, obra defundamental importância para quem quiser estudar o negro na Bahia e o candomblé. L embrando que, àquela altura, Roger Bastide e M elville H erskovits estavam apenas começando suas pesquisas de campo sobre o negro no Brasil.

\section{A criação do CEAO}

Q uando se realizou, em 1959, em Salvador, o 2ํ Colóquio de Estudos Luso-Brasileiros, chegou à Bahia o professor George Agostinho da Silva, um português que tinha se auto-exilado no Brasil depois de haver sido perseguido pelo governo de Salazar. Agostinho propôs ao então reitor da U niversidade da Bahia, E dgar R ego dos Santos, a criação de um Centro de Estudos Afro-O rientais.

O C entro foi criado e retomaram-se, então, os estudos sobre os negros na Bahia. Foram convidados para integrar esse núcleo, por Agostinho da Silva, o antropólogo Vivaldo da Costa Lima, o jornalista N elson de Sousa Araújo e eu, que, a esse tempo, era apenas um professor de geografia interessado em estudos africanos. Foi com esse grupo que o Centro de Estudos Afro-O rientais começou suas atividades.

A primeira coisa que fizemosfoi tentar aprender coisas que os pesquisadores brasileiros, que nos antecederam, não sabiam. Eles nunca haviam estado na África. A penas a conheciam por meio do que fora escrito sobre os africanos, no Brasil, por $\mathrm{N}$ ina R odrigues e Arthur Ramos, entre outros. Então, Vivaldo da C osta Lima foi mandado para a África. Ali ficou por três anos, como professor da U niversidade da Bahia, pesquisando e trabalhando na N igéria, no D aomé (o atual Benin), em Gana e em outros países da África O cidental.

Q uando esse antropólogo voltou à Bahia, decidimos passar para a população da Bahia, especialmente para os negros baianos, o que havíamos aprendido tanto pela leitura dos clássicos como nas pesquisas na África. I niciamos, de modo regular, e por vários anos, uma série de cursos, que apresentavam títulos sugestivos e inéditos até então no Brasil, como: H istória da África N egra, Geografia Regional da África N egra e Culturas A fricanas no Brasil.

As aulas não eram especialmente destinadas a professores, nem somente para os que tivessem um curso superior, mas a to dos os que possuíssem condições de ler e escrever e estivessem interessados no assunto. Assim, a afluência foi enorme, porque os negros baianos, que não freqüentavam ginásios ou faculdades, encontraram nesses cursos uma possibilidade de conhecer melhor a si mesmo. 


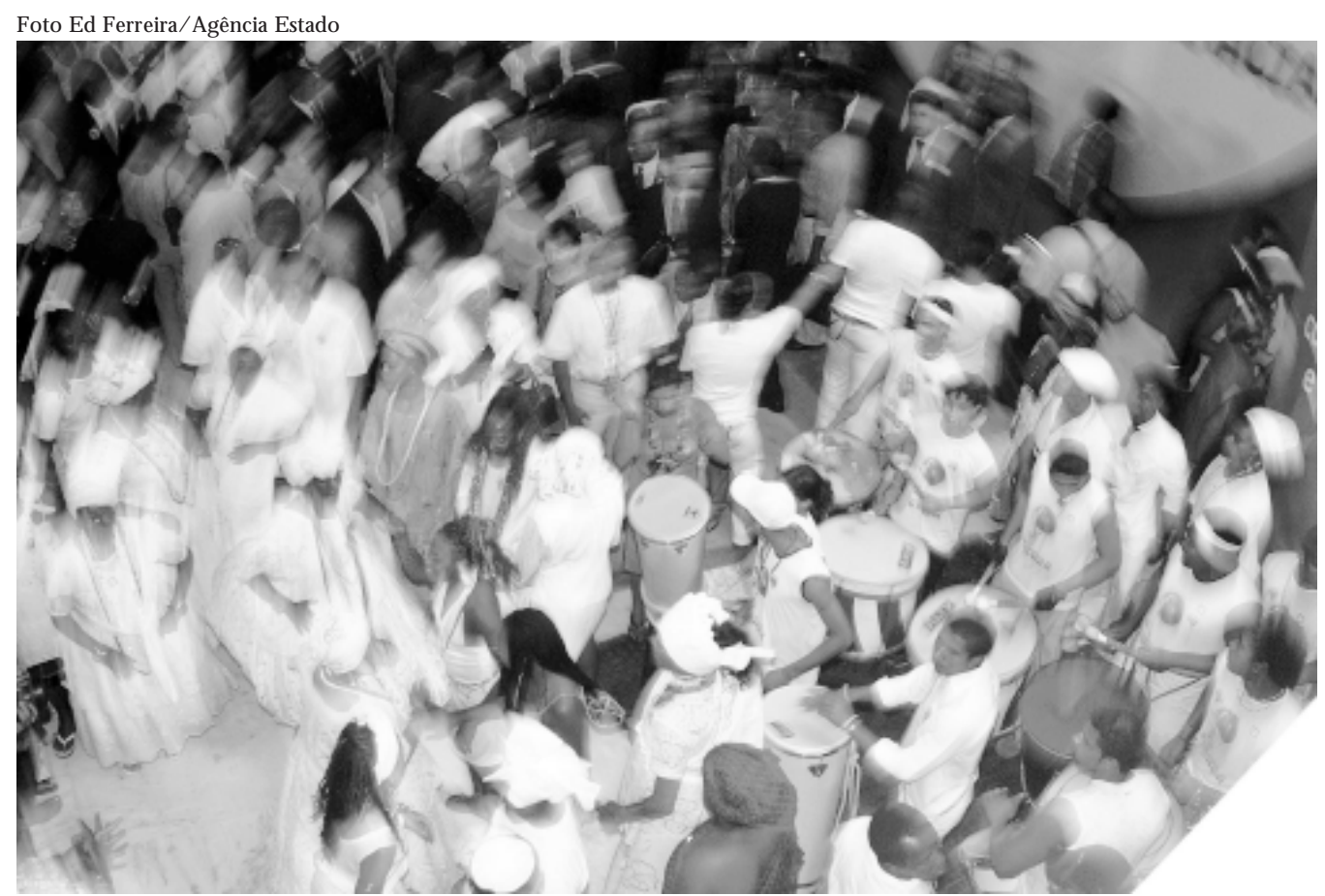

Braślia: membrosdo candombléna instalação da Secretaria de Promoção da I gualdade R acial.

A mentalidade do negro baiano, numa sociedade patriarcal como a da Bahia, era a de um excluído. 0 negro era realmente discriminado; mas isto se dava, de modo essencial, por sua ignorância, pelos seus hábitos, não por uma questão de cor. Tanto que existia entre nós uma expressão que se colocava entre aspas "brancos da Bahia", que se referia a pesso as que nem sempre eram tão "brancas", mas desfrutavam de posição de algum relevo na sociedade. O u seja, o preto que subia socialmente, de certo modo, era considerado branco. Porque as categorias "branco" e "preto", na Bahia, eram, muitas vezes, decorrentes da ascensão social de cada um. Assim, à cor negra se somavam a falta de instrução ou a falta de um emprego de prestígio. Em conclusão, havia um relacionamento muito estreito entre essas três coisas: - negro, pobre e ignorante.

Q uando esses cursos foram oferecidos, os pretos tiveram a oportunidade de aprender que eles tiveram uma $\mathrm{H}$ istória antes de ser trazidos para cá. Compreenderam que não tinham sido os brancos que foram buscá-los como escravos na Á frica. M as que os compraram de outros negros. C onheceram a sua história e aprenderam, também, a geografia das terras de onde foram trazidos.

E ntenderam, ainda, o que significava a cultura dita "negra", pois nunca falávamos em cultura negra. Dizíamos sempre "culturas africanas", porque sabíamos que não existe uma "cultura negra" e sim que há culturas africanas variadas, já que a Á frica N egra é um conjunto de culturas de uma complexidade imensa. Só num país, por exemplo, como Camarões, fala-se mais de cem dialetos. 


\section{0 ensino da língua iorubá}

A partir desse momento, os negros baianos começaram a entender que não havia razão para ficarem envergonhados de sua condição de negros. Batalhamos, nesse particular, o mais que nos foi possível. Trouxemos um professor de língua iorubá, o popularmente chamado nagô, que era a língua de uma parte dos escravos que vieram para o Brasil. Todavia, nem todos os negros falavam o nagô e nem todos se comunicavam em iorubá.

A etnia que teve maior número de escravos, na cidade de Salvador, contudo, falava iorubá. Esta língua veio junto com o candomblé e nele continua a ser usada. Tornou-se, porém, com o tempo, um iorubá deformado. (0 iorubá é uma língua tonal, na qual cada vogal tem três tons: um baixo, um médio e um alto.) Essa diversidade tonal já havia se perdido, no passado, na Bahia, e os cantos em iorubá, entoados no candomblé, não tinham mais qualquer significação semântica para os seus praticantes, que continuavam a considerá-los sagrados, mas que não sabiam mais o que estavam cantando. Somente algumas poucas mães-de-santo tinham ainda uma certa noção sobre o que aqueles cantos representavam. M as elas próprias também não eram mais capazes de manter um diálogo em iorubá, de falar 0 iorubá da antiga N igéria.

Trouxemos, então, para a Bahia, um professor de iorubá formado em O xford, Ebenezer Latunde Lasebikan. Q uando ele chegou, a primeira coisa que quis fazer não poderia dar certo - ressuscitar o iorubá do passado. As comunidades locais do candomblé rejeitaram devolver ao iorubá a tonalidade perdida. 0 iorubá que eles sabiam, entendessem ou não, era aquele ali, e ninguém de fora teria o direito de dizer que estavam errados.

D epois, quando olhei as pessoas que haviam se inscrito no curso de iorubá, verifiquei que entre elas não havia nenhum professor de escola secundária, nenhum professor universitário, nenhum lingüista. Fui apurar a procedência dos freqüentadores do curso e constatei que todos ou quase todos eram do candomblé, "gentede-santo", como chamamos aqui. Concluí, então, que aqueles alunos desejavam aprender o iorubá somente para ter a possibilidade de ascensão dentro da estrutura hierárquica do culto, da sua "casa-de-santo".

Esse fato provocou, inclusive, uma observação maliciosa que ouvi de René Ribeiro, que havia percebido aquele quadro. E le me perguntou, certa feita, como estava indo a minha escola de "pais-de-santo". N o começo, senti vontade de responder com agressividade. $\mathrm{M}$ as compreendi, depois, que ele estava coberto de razão. Estudei, então, uma maneira de acabar com aquele curso, porque o mais importante seria devolver ao negro baiano não a sua antiga língua, mas a dignidade que ele havia perdido por desconhecer sua história e o seu passado, disso podendo orgulhar-se.

M as, naquela ocasião, aconteceu a descolonização, a transformação das colônias africanas em países independentes e ganharam relevo a negritude e 0 
movimento black nos Estados U nidos. O negro baiano começou a sentir-se como um grupo, que passou a ter orgulho da sua condição de negro, mas também a se considerar espoliado pela sociedade branca do passado.

Foi quando começou a ganhar força, na Bahia, um preconceito às avessas, um preconceito do preto contra o branco, chegando a se pôr em questão a legitimidade de um branco, como eu, ser o diretor do CEAO. Achavam que, por ser ele uma instituição de estudos africanistas, deveria ser dirigida por um negro.

\section{A criação dos grupos carnavalescos}

ESTUd os A VANÇADos - Professor, em que ano foi fundado o Centro?

Waldir Freitas deOliveira - Em 1959 e fui diretor do CEAO de 1961 a 1972. Em 1972 já havia essa insatisfação do preto contra o branco. Logo depois começaram a surgir na Bahia grupos carnavalescos exclusivamente de negros. E foi por meio do carnaval que essa intolerância negra contra o branco se fortaleceu, pois surgiram blocos que não aceitavam a inclusão de elementos brancos. Lembrando, no entanto, que antes disso era comum, em Salvador, a existência de blocos de brancos que não aceitavam negros. $\mathrm{N}$ a opinião desses novos blocos negros, eles deveriam ser exclusivamente de negros, por desejarem mostrar que o negro é capaz de fazer, sozinho, al guma coisa tão importante quanto o branco. Q ueriam, assim, também, valorizar sua própria cultura e rejeitar uma outra que Ihes havia sido imposta.

E STU D OS A VAN ÇA D OS - Esse comportamento continua atualmente?

Waldir Freitas Oliveira - Esses blocos continuam rejeitando a presença dos brancos, afirmando que existe um carnaval negro, independente do carnaval baiano. M as $\mathrm{O}$ s Filhos de $\mathrm{G}$ andhi é, no entanto, um clube no qual nunca houve, de modo declarado, esse preconceito, porque dele participam, até hoje, brancos e pretos. Todavia, essa não éa posição do I lêA yê, do M alê D ebalê ou do O lodum. Este último, contudo, recentemente, mudou um pouco essa prática, porque descobriu um caminho comercial novo, com menos intransigência, para vender seu produto. A partir desse viés comercial, passaram a admitir também elementos brancos nas suas fileiras, porque se não os aceitassem, estariam perdendo mercado. M as o Ilê Aiê e um outro bloco, o M alê D ebalê, não sei se alguns outros mais, não admitem a presença de brancos nas suas fileiras. J ustificam essa atitude dizendo que estão valorizando seu passado cultural. Com isso passou a existir, na Bahia, talvez como no passado, um carnaval essencialmente negro, como elemento isolado dentro do conjunto do carnaval baiano.

Esse preconceito do negro contra o branco encontra, naturalmente, defensores que agora caminham no sentido de apoiar a tese da reparação, a exigirem que a sociedade brasileira pague à população negra atual os prejuízos sofridos pelos negros no passado. 


\section{A questão das cotas}

E STU D OS A VA N ÇA D os - O sr. poderia explicitar sua opinião a respeito do problema das cotas nas universidades públicas para os afro-descendentes?

Waldir de Frei tasOliveira - Há, evidentemente, uma necessidade de se abrir espaço nas universidades públicas para os afro-descendentes, mas não por serem exclusivamente afro-descendentes. A característica fundamental do ensino na Bahia, pelo menos, e talvez no Brasil todo, é que o branco cursa colégios particulares, enquanto o preto vai para a escola pública. Em razão disso devemos encontrar um jeito de combinar o critério da etnicidade com o critério da escola pública, para abrir as portas das universidades aos egressos da rede pública de ensino, bem mais democrática em sua organização e funcionalidade que as escolas da rede privada, sem a preocupação de identificá-los como afro-descendentes ou não.

Se privilegiarmos o preto para entrar na universidade, mesmo que ele não tenha preparo suficiente, iremos liquidar com a qualidade do ensino nas universidades. O u, então não fará mais diferença o indivíduo ter, ou não, o conhecimento necessário para entrar na universidade.

H á uma semana, assisti à formação de duas turmas de cursos de nível universitário, um de administração hospitalar, outro de comércio exterior. A metade pelo menos dos formandos era composta por pretos e mulatos. Essa universidade é particular e nela estudam os pretos que podem pagar as mensalidades. N inguém ali pergunta se eles são brancos ou pretos. Fui, também, professor de cursinho de vestibular, durante muitos anos, e sei que a pessoa que estuda em colégio particular, ou freqüenta um cursinho, tem maior possibilidade de passar no vestibular e entrar na universidade. O s brancos, freqüentadores, em sua maioria, dos cursinhos, formam, então, talvez oitenta por cento da população das universidades públicas brasileiras. Assim, nelas são poucos os pretos, isto não se devendo, porém, à sua cor, mas porque não tiveram eles, nem seus familiares, dinheiro para pagar escolas particulares ou esses cursinhos.

\section{Q uem é branco e quem é preto?} branca?

ESTUdos A van ÇADos - Como se deveria conceituar a população que não é

Waldir de FreitasOliveira - Q uando estudei na França, hospedei-me na C asa do Brasil, em Paris, e mantinha longas conversas com um homem exemplar, maravilhoso, por todos conhecido, que se chamava Américo J acobina L acombe. $U$ ma vez falou-me de certos documentos que encontrara na Biblioteca de Paris. Tratava-se, inicialmente, de uma carta escrita no fim do século XIX, na qual o governo francês escrevia para seu embaixador, no R io de J aneiro, perguntando 0 que iria acontecer no Brasil, com a abolição da escravatura e se os negros iriam tomar o poder no país. 0 governo francês mostrava-se, naturalmente, preocupado com o que havia acontecido em São Domingos, atual $\mathrm{H}$ aiti. $\mathrm{O}$ embaixador respondera, então, dizendo para não se preocupar com isto, porque ele só conhecia 
como brancos, no Brasil, os membros da família Bragança, a de D. Pedro II . O u seja, já havia no país, a esse tempo, como se deduz, uma miscigenação acentuada, em uma época na qual não havia ainda começado, de modo intenso, a corrente migratória de europeus. O Brasil, já era, portanto, um país de mulatos. Q uem enxergou e declarou isso, pela primeira vez, foi, talvez, D arcy Ribeiro.

$\mathrm{N}$ ão sei, na realidade, quem é branco e quem é preto, no Brasil. Se formos adotar o princípio norte-americano de que negro é quem possui um oitavo de sangue negro, vamos cair na mesma esparrela que eles caíram. Se formos apurar aqui as ascendências de cada um, acabaremos por endossar a tese de Gilberto Freyre, de que toda história de família brasileira passa, obrigatoriamente, pela beira do rio ou pela cozinha.

Dizendo, porém, que sempre existirá, nessa história, lugar para uma lavadeira mulata ou preta, ou uma cozinheira mulata ou preta, não será por aí que poderemos avaliar a situação. Q uem deve se definir como negro, branco, mulato ou afro-descendente é o próprio indivíduo.

\section{As categorias do I BG E}

Carlos $\mathrm{H}$ asenbalg, sociólogo de muita fama no Brasil, talvez tenha sido quem sugeriu ao I BGE colocar no censo demográfico as categorias brancos, pardos e negros.

Contra a qualificação de "pardos" houve, no entanto, a opinião de um antropólogo norte-americano de grande valor, o saudoso $\mathrm{M}$ arvin $\mathrm{H}$ arris. Trabalhei com ele em 1992 em Rio de Contas, uma cidade do interior baiano. Ele elaborou, naquela ocasião, um quadro no qual apareciam doze desenhos de caras de pessoas, feitos por um desenhista especializado, retratando vários tipos de feição facial. Interrogávamos a cada inquirido, com quem ele achava que se parecia, para saber se ele se considerava branco, mulato, negro e assim por diante. $\mathrm{M}$ arvin $\mathrm{H}$ arris queria que fosse excluída a expressão "pardos" dos quadros referenciais dos recenseamentos brasileiros. Posteriormente, ele escreveu sobre o assunto um artigo denominado "Who are White?", que foi publicado em Social Forces, mas, infelizmente, nunca foi traduzido para o português.

Aqui, em Salvador, quando olhavam para mim, na infância ou na adolescência, nunca me chamaram de branco, que significava ser "alvo", o que eu não era, mas de "moreno". E ssa expressão, "moreno", era muito usual. H avia famílias brancas nas quais havia "alvos" e "morenos". O s que não eram "alvos", tão "brancos", assim como eu, eram chamados de "morenos". N ão sei se em outro lugar era assim também. Fora daí havia os pretos e os mulatos.

Existia, também, uma variedade enorme de denominações para os tipos raciais. $M$ as 0 que acontecia era que cada um desses tipos possuía uma posição firmada e conhecida dentro da sociedade. Os brancos, incluindo os morenos, eram os donos da bola, os que dirigiam a sociedade. Os mulatos procuravam seguir os modos de ser, os hábitos e os costumes dos brancos, para se igualarem 
a eles e usufruir seus privilégios. Enquanto os pretos, sem instrução, quase sempre analfabetos e pobres, não podiam se revelar como eram, não tinham mesmo uma concepção exata de si próprios.

\section{A questão religiosa}

EStUd os AvançAdos - Como o senhor vê essa relação entre o problema religioso e os negros, na Bahia?

Waldir de Freitas Oliveira - O problema afro-religioso na Bahia já foi muito mais importante, pois houve uma época em que as casas de candomblé representavam osúnicos núcleos de resistência negra contra o predomínio da cultura branca. As mães-de-santo eram obedecidas, exerciam uma posição de liderança inegável sobre a população negra. 0 candomblé deixou de ser, contudo, ao meu ver, essa coisa vital para o negro baiano. $\mathrm{M}$ as no passado foi essencial. $\mathrm{N}$ aturalImente, por sua importância, era um culto perseguido. As mães-de-santo perderam, no entanto, muito de seu antigo prestígio e seus lugares foram, aos poucos, ocupados por aqueles que hoje levantam a bandeira da negritude, da reparação, da identidade negra, sem se afastar, por completo, do candomblé, mesmo no Carnaval.

\section{M useu Afro-Brasileiro}

Q uando se pensou na criação do M useu Afro-Brasileiro, eu era diretor do CEAO . O professor M ichel Parent, inspetor dos monumentos históricos do M inistério da Cultura da França e então consultor da U nesco junto à então chamada $\mathrm{D}$ iretoria do Patrimônio $\mathrm{H}$ istórico e Artístico $\mathrm{N}$ acional, veio à Bahia em meados de 1967, a fim de discutir comigo e planejar, em conjunto com outras pessoas, a instalação desse museu. M as os participantes mais atuantes dos movimentos negros queriam que ele se chamasse $\mathrm{M}$ useu do $\mathrm{N}$ egro. $\mathrm{M}$ anifestei minha discordância e defendi a idéia de que ele deveria ser denominado $M$ useu Afro-Brasileiro. Argumentei que se fosse criado um M useu do N egro, teríamos a obrigação de também organizar um Museu do Mulato, um outro do Caboclo, assim como outros museus referentes aos vários tipos raciais componentes da sociedade brasileira. Porque eu não via e não vejo o negro no Brasil como uma unidade, mas como uma mescla cultural. 0 representante da U nesco concordou e o museu acabou sendo criado, e se mantém com o nome de M useu Afro-Brasileiro, integrado à U niversidade Federal da Bahia. Continuo a pensar que agi certo naquela ocasião. 